\title{
PENGEMBANGAN BUKU ELEKTRONIK UNTUK SAINS DI SMP SBI DAN RSBI
}

\author{
Diana Rochintaniawati (diana_rochintaniawati@upi.edu) \\ Ari Widodo \\ Tuszie Widhiyanti \\ International Program On Science Education FPMIPA UPI
}

\begin{abstract}
Research and development ( $R \& D$ ) of electronic books (e-book) for science in International Secondary Schools (RSBI and SBI) were conducted with the objective of providing science e-books as a source of learning for teachers and students of RSBI and SBI. With the development of this e-book, it was expected to develop an integrated understanding of science in students, develop students' language skills, and to develop skills in using information technology. The study was conducted by the method of $R \& D$ that begins with an analysis of national science curriculum and Cambridge curriculum. The e-book was presented in the form of integrated themes that combined concepts of physics, chemistry and biology written in English. From the results of feasibility study conducted on the use of the e-books it was found that the e-books were sufficiently met the criteria in terms of image presentation, animation, font used, English, exercises and student activities. In general, it was concluded that the e-book developed was creatively made and appropriate for learning source in secondary schools, particularly in RSBI and SBI.
\end{abstract}

Keywords: RSBI / SBI secondary schools science, science e-book

\begin{abstract}
ABSTRAK
Penelitian Pengembangan Buku Elektronik untuk Sains di SMP SBI dan RSBI dilakukan dengan tujuan untuk menyediakan buku sains yang dapat dijadikan sebagai salah satu sumber belajar bagi guru dan siswa SMP di RSBI/SBI. Dengan dikembangkannya buku ini, diharapkan pembelajaran sains dapat mengembangkan pemahaman sains siswa yang terintegrasi, mengembangkan kemampuan berbahasa siswa, serta mengembangkan kemampuan dalam menggunakan teknologi informasi. Penelitian dilakukan melalui metode Reseach and Development (R\&D) yang diawali dengan analisis kurikulum sains SMP berdasarkan KTSP dan kurikulum Cambridge. Penyajian buku berupa tema-tema yang mengintegrasikan konsep-konsep dalam fisika, kimia dan biologi dengan menggunakan Bahasa Inggris sebagai bahasa pengantar. Dari hasil uji kelayakan penggunaan buku yang dilakukan terhadap siswa SMP diperoleh bahwa e-book yang disusun memenuhi kriteria penggunaan e-book dalam aspek penyajian gambar, animasi, penggunaan huruf, penggunaan Bahasa Inggris sebagai bahasa pengantar, latihan serta kegiatan siswa. Secara umum, e-book yang dikembangkan dinilai memiliki kreativitas yang baik dan layak digunakan sebagai buku sumber dalam pembelajaran sains di SMP, khususnya di $\mathrm{RSBI} / \mathrm{SBI}$.
\end{abstract}

Kata kunci: buku elektronik sains, pembelajaran sains di RSBI/SBI 
Pendidikan Indonesia dimasa depan diproyeksikan untuk dapat bersaing secara global. Untuk kepentingan tersebut, maka pemerintah menggulirkan Program Sekolah Bertaraf Internasional ditujukan untuk meningkatkan kualitas pendidikan di Indonesia agar mampu menghasilkan lulusan yang memiliki daya saing internasional.

Ada tiga permasalahan yang dapat dicermati dalam penyelenggaraan pembelajaran sains pada jenjang Sekolah Menengah Pertama (SMP) di Indonesia, khususnya di sekolah bertaraf internasional (RSBI). Pertama, pembelajaran sains yang dahulu diselenggarakan terpisah melalui pembelajaran biologi dan fisika menjadi pelajaran sains yang merupakan gabungan antara mata pelajaran biologi, kimia dan fisika. Hal ini menjadi sebuah tantangan bagi guru karena guru yang ada saat ini adalah guru mata pelajaran biologi, fisika dan kimia bukan guru yang dididik untuk menjadi guru sains. Kedua, penggunaan Bahasa Inggris sebagai bahasa pengantar mata pelajaran sains. Ketiga adalah penggunaan ICT dalam melangsungkan proses pembelajaran (Sustinawati, 2009).

Salah satu hal yang dapat dilakukan untuk dapat membenahi ketiga masalah di atas adalah dengan mengembangkan buku pelajaran sains yang dirancang untuk memfasilitasi karakteristik pembelajaran sains di RSBI. Untuk itu, perlu dikembangkan suatu buku pelajaran sains untuk SMP yang menyajikan materi sains secara terintegrasi (integrated science), disertai dengan media pendukung yang berisi materi-materi pengayaan yang mudah digunakan oleh siswa. Hal ini didasarkan pada pemikiran agar pembelajaran sains di SMP dapat mengembangkan pemahaman siswa tentang sains secara terintegrasi, mengembangkan kemampuan berbahasa siswa, serta mengembangkan kemampuan dalam menggunakan teknologi informasi.

Penelitian ini bertujuan untuk menghasilkan buku pelajaran sains terintegrasi yang dapat digunakan dalam penyelenggaraan pembelajaran sains di SBI/RSBI.

\section{METODOLOGI}

Metode yang digunakan dalam penelitian adalah Research and Development $(R \& D)$ yang dikembangkan oleh Borg and Gall (2003). Penelitian diawali dengan melakukan analisis terhadap KTSP dan kurikulum Cambridge untuk mengidentifikasi tema-tema sains yang dapat diintegrasikan antara biologi, fisika dan kimia. Penelitian diakhiri oleh studi validasi terhadap buku yang dikembangkan melalui implementasi pembelajaran dengan menggunakan e-book sebagai sumber belajar dan dilakukan di sekolah yang menggunakan bahasa pengantar bilingual.

\section{HASIL DAN PEMBAHASAN}

Penelitian ini diawali dengan penyusunan buku elektronik (e-book) yang dilengkapi dengan media audio visual. Program yang digunakan untuk menyusun buku ini adalah program flash untuk menampilkan gambar-gambar yang dapat bergerak dan dilengkapi dengan suara. Penyusunan buku melibatkan delapan orang mahasiswa IPSE (International Program on Science Education) FPMIPA UPI yang sedang menempuh semester enam dan satu orang mahasiswa Ilmu Komputer (ILKOM) sebagai instruktur program flash yang digunakan dalam menyusun e-book.

Langkah penelitian diawali dengan memilih delapan orang mahasiswa untuk terlibat dalam penyusunan buku elektronik (e-book). Langkah selanjutnya adalah mengidentifikasi Standar Kompetensi dan Kompetensi Dasar dari Standar Isi PERMEN No. 22 Tahun 2006 serta kurikulum Cambridge untuk memadukan SK dan KD dan materi materi biologi, fisika dan kimia yang memungkinkan untuk diintegrasikan dan melakukan studi literatur terhadap konsep-konsep fisika, kimia dan biologi sesuai dengan bab yang telah ditentukan. Penelti memberikan kebebasan pada mahasiswa untuk menentukan tema-tema yang akan mereka susun. Setelah mahasiswa 
menentukan tema-tema, mereka dilibatkan dalam kegiatan workshop program flash yang diberikan oleh instruktur yaitu mahasiswa IImu Komputer (ILKOM).

Penyelenggaraan workshop dilakukan sebanyak delapan kali selama tiga bulan. Secara berkala satu minggu sekali mahasiswa dan peneliti bertemu dengan instruktur untuk mempelajari program flash dan menyusun buku dengan menggunakan program tersebut. Konsultasi antara peneliti, mahasiswa dan instruktur dilakukan secara kontinyu untuk memamtau perkembangan penyusunan buku. Tema-tema yang ditentukan untuk bab buku adalah: Wave and Sound, Environmental Maintenance serta Acid, Base and Salt.

Gambar 1, 2, 3, dan 4 merupakan contoh e-book yang dikembangkan dalam penelitian.

Setelah buku selesai disusun, dilakukan uji kelayakan penggunaan e-book, Uji coba kelayakan dilakukan di satu sekolah yang menggunakan bahasa pengantar bilingual dalam pembelajaran sains. Berdasarkan hasil uji coba kelayakan diperoleh hasil lebih dari 80\% siswa memberikan respon positif terhadap e-book yang disusun peneliti. Siswa menyatakan bahwa e-book yang disusun menarik dan layak untuk digunakan sebagai sumber belajar sains. Lebih dari $80 \%$ siswa berpendapat bahasa yang digunakan dalam e-book mudah dicerna meskipun menggunakan bahasa Inggris. Menurut sebagian besar siswa, penggunaan bahasa Inggris dalam e-book yang disusun dapat memacu mereka untuk lebih mempelajarai bahasa Inggris.

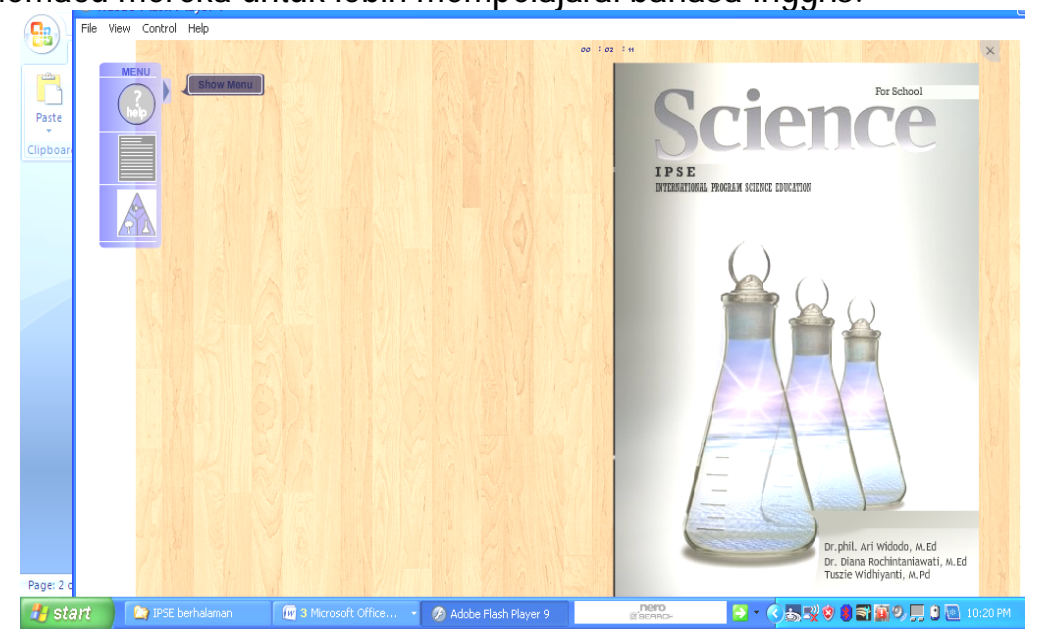

Gambar 1. Sampul depan e-book

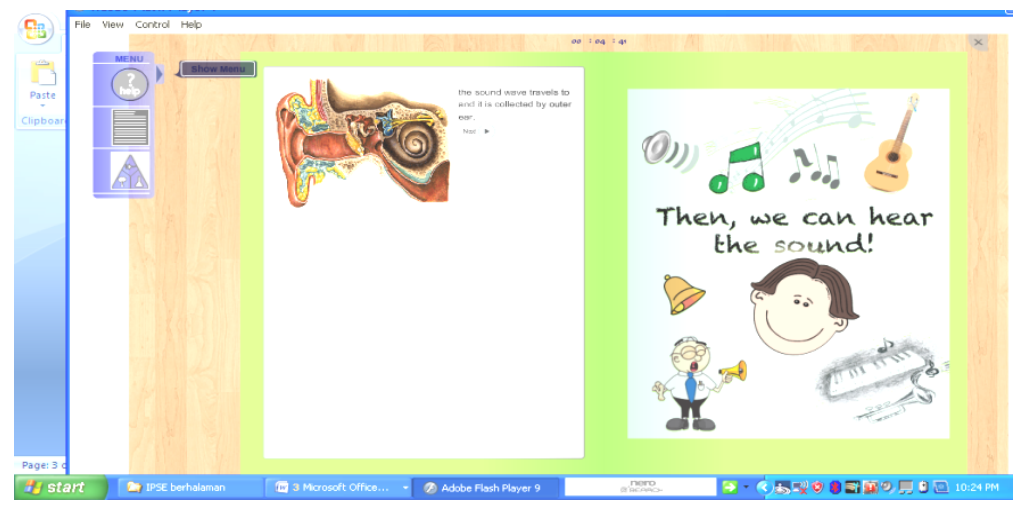

Gambar 2. Contoh e-book dengan halaman yang memiliki animasi 


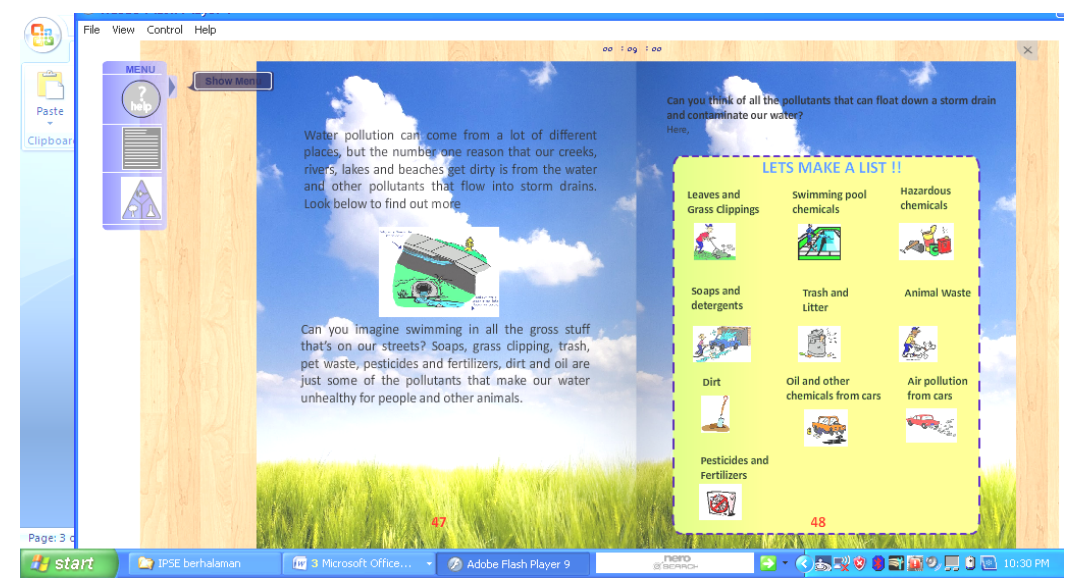

Gambar 3. Contoh e-book untuk halaman yang memiliki kegiatan puzzle

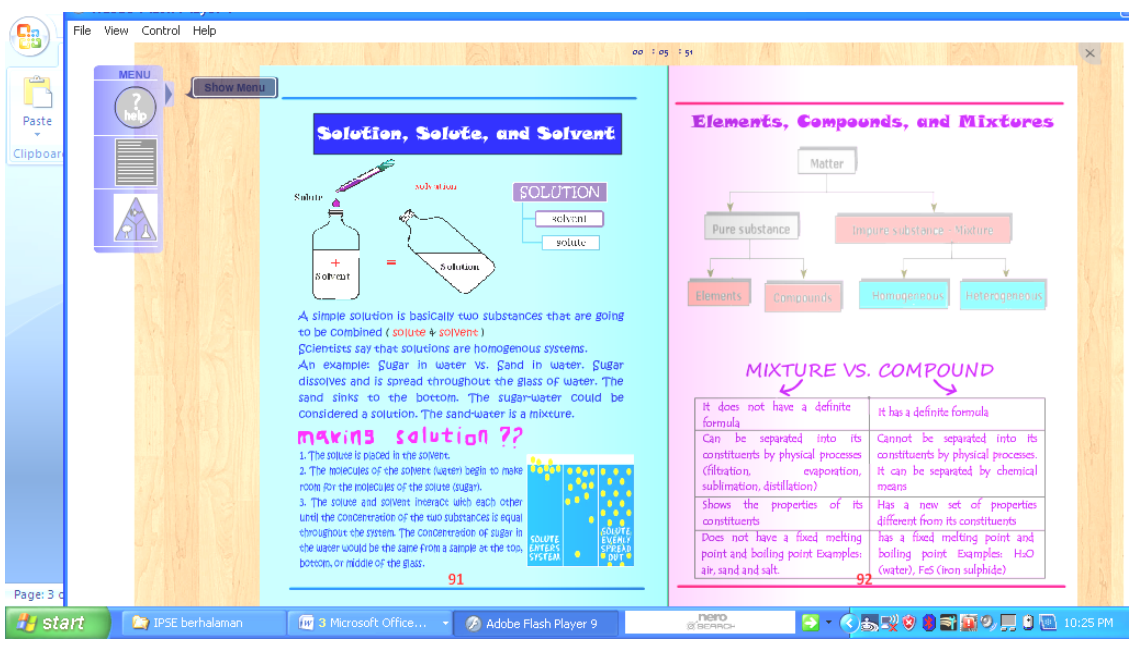

Gambar 4. Contoh e-book dengan halaman yang berisi kegiatan praktikum

Besarnya huruf yang digunakan dalam e-book yang disusun sudah sesuai, sehingga memudahkan mereka untuk membacanya. Penyajian gambar, adanya animasi dan permaian di dalam e-book dinilai sebagai suatu hal yang menarik bagi siswa. Lebih dari $80 \%$ siswa menyatakan bahwa e-book yang disusun memiliki kreativitas yang tinggi, sehingga dapat meningkatkan minat siswa untuk membaca e-book tersebut.

Kedalaman konsep yang terdapat di dalam e-book dinilai memadai untuk siswa SMP. Selain itu e-book yang dikembangkan dinilai dapat membantu mereka untuk memahami materi-materi sains secara terintegrasi. Hasil pretest dan posttest yang diberikan pada siswa kelas VII, VIII menunjukkan adanya peningkatan rata-rata gain sebesar 25 dan 28. Dengan menggunakan kategorisasi Arikunto (2006), peningkatan rata rata sebesar 25 dan 28 termasuk ke dalam peningkatan tergolong sedang.

Berdasarkan kuesioner yang diberikan pada siswa, diperoleh hasil sebanyak 70\% siswa menyatakan bahwa tema-tema yang mengintegrasikan antara satu subjek dengan subjek lain membuat mereka memahami bahwa subjek-subjek dalam sains memiliki keterkaitan antara satu 
dengan lainnya. Dengan kata lain bahwa subjek-subjek sains dapat dipelajari secara terintegrasi. Dalam aspek isi, konsep yang disajikan dalam e-book yang dikembangkan dinilai aktual dan penyajian contoh masalah relevan dengan kehidupan sehari-hari.

Hanya sebagian kecil dari siswa (kurang dari 20\%) yang menyatakan bahwa tulisan atau huruf yang digunakan dalam e-book terlalu kecil dan penggunaan bahasa Inggris pada e-book menyulitkan mereka untuk memahami isi dari e-book. Namun secara keseluruhan, siswa menyatakan bahwa e-book yang disusun merupakan buku elektronik yang menarik karena berisi animasi, gambar-gambar yang menarik dan permainan-permainan (puzzles).

Berdasarkan jenisnya, E-book yang dikembangkan pada penelitian ini merupakan e-book terdatabase ber-hypermedia yang dibuat dengan bantuan programmer. E-book ini berformat flash yang disimpan di dalam Compact Disk (CD) agar siswa mudah membawanya dan juga dapat dibaca kembali di rumah. E-book ini memiliki beberapa kelebihan, yaitu sumber belajar yang menuntut interaksi dengan siswa. Jenis interaksi yang terjadi mulai dari men-drag mouse untuk membuka halaman; mengklik mouse untuk membuka video, animasi, membuka hypermedia offline dan memilih jawaban yang dapat memberikan umpan balik; mengarahkan kursor untuk menampilkan glosarium dan keterangan gambar. Interaksi lainnya berupa mengetik dengan menggunakan keyboard komputer.

Selain itu, e-book yang dikembangkan pada penelitian ini dilengkapi dengan sistem database yang dapat merekam aktivitas siswa saat memakai e-book dengan menggunakan aplikasi perekam Camtasia Studio 6. E-book merupakan salah satu bentuk sumber belajar yang dibuat dengan tujuan untuk memfasilitasi siswa belajar sesuai dengan kecepatan belajarnya dan gaya belajarnya, karena pada e-book ini terdapat multimedia interaktif. Menurut Munadi (2008) multimedia interaktif dapat digunakan dalam pembelajaran dan berpengaruh cukup efektif untuk meningkatkan hasil belajar siswa.

Informasi-informasi dalam e-book akan didapatkan oleh siswa jika siswa berinteraksi dengan e-book tersebut. E-book yang digunakan memiliki beberapa komponen, di antaranya adalah materi berupa teks, video, animasi, game, gambar, glosarium, dan test interaktif. Komponen-komponen tersebut dikemas sedemikian rupa sehingga bisa membantu siswa untuk memahami konsep yang abstrak. Berdasarkan penelitian yang sudah dilakukan, terdapat kelebihan dalam penggunaan electronic book sebagai sumber belajar, di antaranya: memberikan iklim pembelajaran yang positif dan sejalan dengan konstruktivisme (Nugraha, 2009; Permana, 2010), meningkatkan motivasi belajar siswa yang didukung oleh peningkatan minat belajar siswa dalam mempelajari biologi (Fransiska, 2009). Hal ini dikarenakan terdapat beragam gambar, video, animasi, dan suara pada e-book, memberikan umpan balik pada siswa dengan menggunakan test dan game pada e-book.

Berdasarkan hal-hal tersebut, maka dapat dikatakan bahwa e-book dapat digunakan secara optimal dengan pengawasan oleh guru dalam pembelajaran. Hal ini sejalan dengan prinsip konstruktivisme, seperti yang terdapat dalam Widodo (2009) dan Baki (2010) mengenai lima kunci kriteria lingkungan pembelajaran konstruktivisme, yaitu: (1) adanya fasilitas pembelajaran untuk siswa. Dengan fasilitas dan sarana yang diberikan, diharapkan siswa lebih berperan aktif dalam membangun pengetahuan sehingga pengetahuannya menjadi semakin luas, (2) relevansi dan kebermaknaan pengalaman pembelajaran. Disini siswa menerapkan relevansi dan kebermaknaan belajarnya, seperti dalam diskusi, percobaan, dan sebagainya, (3) interaksi sosial yang kondusif. Hal ini berkaitan dengan aspek negosiasi, dimana siswa diberi hak untuk bersikap aktif dan terbuka dalam setiap komunikasi baik antar siswa dan siswa dengan guru, (6) dorongan (pemberian semangat atau motivasi) untuk menjadi pembelajar yang mandiri yaitu pembelajar bertanggung jawab terhadap proses belajarnya. 


\section{KESIMPULAN}

E-book yang dikembangkan dengan format flash. secara umum direspon positif oleh siswa. Penggunaan variasi penyajian seperti gambar, animasi, permainan (puzzle) dan kuis dalam e-book menjadi hal yang menarik bagi siswa. Penyajian konsep secara tematik membuat siswa lebih memahami sains secara terintegrasi dan penggunaan bahasa Inggris dinilai dapat memotivasi siswa untuk meningkatkan kemampuan siswa dalam penggunaan bahasa Inggris.

\section{REFERENSI}

Arikunto, S. (2006). Prosedur penelitian: Suatu pendekatan praktek. Jakarta: Penerbit Rineka Cipta. Borg, W., \& Gall, M. (2003). Educational research: An introduction. USA: Pearson Education Inc.

Baki, A. (2010). E-book usage of graduate students studying educational sciences in Turkiye. Turkish online journal of distance education-TOJDE, January, Vol. 11, (198-210).

Fransiska. A. (2009). Pengaruh buku elektronik terhadap hasil belajar siswa dalam konsep sistem pencernaan manusia. Skripsi sarjana yang tidak dipublikasikan, jurusan pendidikan biologi.

Munadi, Y. (2008). Media pembelajaran sebuah pendekatan baru. Jakarta: Gaung Persada.

Nugraha, E. J. (2009). Influence e-book of biology student learning outcomes in the concept of environmental pollution. Tesis master yang tidak dipublikasikan, Universitas Pendidikan Indonesia, Bandung.

Permana, S. (2010). Pengaruh penggunaan e-book terhadap hasil belajar siswa pada pembelajaran biologi di SMA. Skripsi sarjana yang tidak dipublikasikan, jurusan pendidikan biologi.

Sutisnawati, A. (2009). Interactive e-Book usage in the learning process in plant hysiology to improve dtudent results RSBI junior class VIII. Tesis master yang tidak dipublikasikan, Universitas Pendidikan Indonesia, Bandung.

Widodo, A. (2009). Effectiveness of e-module-based interactive constructivism in the matter of genetics to improve junior high school biology teachers. Journal of Educational Research, 3(2), 153-163. 